\title{
Práticas de numeramento e relações de gênero: tensões e desigualdades nas atividades laborais de alunas e alunos da EJA*
}

\author{
MARIA CELESTE REIS FERNANDES \\ DE SOUZA \\ Secretaria Municipal de Educação de Governador Valadares, \\ Governador Valadares, MG, Brasil \\ MARIA DA CONCEIÇÃO FERREIRA \\ REIS FONSECA \\ Universidade Federal de Minas Gerais, \\ Belo Horizonte, MG, Brasil
}

\begin{abstract}
Atualmente permeiam os diversos discursos que circulam no campo educacional, ou que o tomam como objeto, a preocupação e de certa forma a esperança de se estabelecerem relações entre o que se aprende na escola e as experiências e demandas laborais de estudantes, especialmente se tais estudantes, em qualquer fase da escolarização, são pessoas adultas, jovens ou mesmo adolescentes. Reflexos dessa preocupação (e dessa esperança) tornam recorrentes nas propostas pedagógicas voltadas para a Educação de Jovens e Adultos (EJA) recomendações explícitas para que se tomem as atividades laborais de alunas e alunos como subsídio e motivação para a abordagem de conteúdos escolares ou como pretexto para a proposição de atividades de cunho didático. ${ }^{1}$
\end{abstract}

* A pesquisa que subsidia este artigo conta com o apoio do Conselho Nacional de Desenvolvimento Científico e Tecnológico ( $\mathrm{CNPq})$.

1 A ênfase nessas recomendações pode ser encontrada nas proposições curriculares oficiais (Ribeiro, 1997; Brasil, 1998; 1999; 2002) e nas orientações dos programas 
Entretanto, o modo como em geral se mobilizam as práticas laborais de estudantes - visando antes ao ensino de determinados conceitos ou procedimentos do conhecimento escolar do que à problematização daquelas práticas - impõe submetê-las a um processo de descontextualização, como ocorre, não raro, por exemplo, quando sobre elas se empreende um procedimento de modelamento matemático. A descontextualização e a adaptação, feitas para que a situação vivida se adéque às finalidades pedagógicas, nesses casos reformatando as relações quantitativas, métricas, de ordenação, de classificação ou de organização do espaço, aos parâmetros da racionalidade que impregnam a matemática da escola, findam por converter as práticas laborais em "pseudopráticas"2 (Walkerdine, 1988) que desconhecem, silenciam e ocultam o intricado jogo de valorações e intencionalidades definidores das práticas matemáticas nas atividades laborais de mulheres e homens, jovens, adultos ou idosos.

Neste artigo, ao evocar as práticas laborais de mulheres e homens estudantes da EJA, buscamos chamar a atenção para a complexidade das relações que envolvem as atividades que as compõem e que conformam os fazeres matemáticos que as constituem, de modo que denuncie o caráter ingênuo e ao mesmo tempo repressor das abordagens escolares que destituem essas práticas dos dramas e das tramas que nelas instauram racionalidades próprias, em muitos aspectos estranhos à racionalidade em que se organizam a escola e a matemática escolar. Em especial, queremos destacar os jogos de poder definidos pelas relações de gênero que impregnam as práticas laborais de alunas e alunos, pessoas jovens e adultas, como um alerta contra a naturalização das desigualdades de gênero que o silenciamento desses jogos - ainda que para fins didáticos - tendem a perpetuar.

Para subsidiar a análise, trouxemos acontecimentos discursivos capturados na vida de alunas e alunos da EJA, trabalhadoras e trabalhadores pertencentes a uma associação de catadoras e catadores de materiais recicláveis. Esses acontecimentos compõem o material empírico de uma pesquisa que investiga as configurações das relações de gênero nas práticas de numeramento protagonizadas por essas mulheres e esses homens. $\mathrm{O}$ material foi produzido em oficinas pedagógicas, pela observação de aulas de EJA que aconteciam no galpão da associação, em entrevistas e registros de episódios narrados pelos sujeitos ou por nós testemunhados ao longo do trabalho de campo.

Destacamos na pesquisa os discursos forjados nas tramas da quantificação e da mensuração, das racionalidades que as regem e que parametrizam as atividades laborais desses homens e dessas mulheres. Nesses acontecimentos, vemos

específicos destinados a sujeitos da EJA, como o Programa Nacional de Inclusão de Jovens: ProJovem Urbano (http://www.projovemurbano.gov.br/site/), ProJovem Campo (http://portal.mec.gov.br/index) e o ProJovem Trabalhador (http://portal.mte. gov.br/politicas_juventude/projovem-trabalhador-1.htm).

2 "Pseudo-practical". O termo pseudopráticas é utilizado por Valerie Walkerdine (1988) referindo-se aos problemas matemáticos utilizados em práticas matemáticas escolares que parecem remeter a um suposto exemplo do uso da matemática na vida real. 
estabelecerem-se os estiramentos provocados pela assimetria nas relações entre homens e mulheres, fabricados por discursos que se deixam permear pela racionalidade matemática de matriz cartesiana, que dispõe lugares discursivos a serem ocupados de modos diferentes por homens e mulheres.

Nossa análise, portanto, toma o exercício de tais atividades como práticas discursivas, articuladas a relações de poder, produção de saberes e instauração de verdades, como as considera Foucault em seus estudos (Foucault, 1988; 1996; 1999; 2005; 2006). Ultrapassando a simples referência a "palavras e coisas", Foucault (1999) se ocupa em mostrar o discurso em funcionamento, isto é, produzindo o que chamamos o real das coisas; e é por isso que dizemos que o discurso na perspectiva foucaultiana é produtivo. $\mathrm{O}$ discurso em funcionamento encontra seu lugar em práticas sociais em que múltiplos discursos disputam espaços para se afirmarem como verdadeiros. Na produção de tais realidades, o discurso em funcionamento envolve relações de poder e produção de saberes - "interfaces do saber e do poder, da verdade e do poder" (Foucault, 2006, p. 229).

Operando com esse conceito de discurso, compreendemos que nas atividades laborais aqui analisadas engendram, e por elas são engendradas, relações de poder-saber: nelas circulam discursos de diversos campos (das matemáticas, da biologia, da psicologia, da linguística, dos movimentos sociais, dos movimentos feministas, do direito, da pedagogia etc.) que nos dizem como são ou devem ser homens e mulheres. Propondo-se a produzir sujeitos de determinado tipo, tais discursos disputam espaços até mesmo nas práticas de contar, medir, ordenar, classificar ou organizar o espaço que conformam aquelas atividades laborais.

Interessa-nos, porém, propor uma compreensão das relações de gênero permeando a constituição de práticas matemáticas de mulheres e de homens, mas não reduzindo a análise à identificação de habilidades matemáticas de homens ou de mulheres, ou a um estudo da abordagem da relação desses sujeitos com a matemática. Preocupa-nos, por isso, que o uso do adjetivo matemáticas para distinguir tais práticas restrinja o olhar para práticas que se podem referenciar diretamente à matemática escolar, o que limitaria as possibilidades de análise da complexidade das práticas envolvidas nessas experiências. Por isso, ocorreu-nos mobilizar o conceito de práticas de numeramento, que permite confrontar a dimensão relacional das experiências de quantificação, ordenação ou mensuração protagonizadas por mulheres e por homens em práticas laborais, remuneradas ou não.

Todavia, as práticas de numeramento das catadoras e dos catadores, alunas e alunos da EJA, são tomadas por nós como práticas de letramento, uma vez que se constituem nas interações no seio de uma sociedade grafocêntrica, em situações de leitura e escrita ou de algum modo marcadas pela cultura escrita: mesmo quando não se faz o uso da tecnologia envolvida no ato de ler e escrever, identifica-se nas práticas orais a marca da cultura escrita como idealização a alcançar, como acessório que se utiliza ou se dispensa, como intimidação à qual se resigna ou se resiste, como validação a que se submetem tais práticas, ou que são por elas questionadas, burladas, desdenhadas (Fonseca, 2010). 
Assim, procuramos nos referenciar em estudos de e sobre letramento, pois são as discussões desse campo, especialmente as dos "novos estudos sobre letramento"3 (Street, 2003), que têm trazido contribuições relevantes à discussão das questões postas pelo uso do conceito de práticas de numeramento como ferramenta analítica. Compreendemos, portanto, que o conceito de numeramento, como o de letramento, não é um "instrumento neutro a ser usado nas práticas sociais quando exigido" (Soares, 2001, p. 74), mas volta-se para "um conjunto de práticas socialmente construídas que envolvem a leitura e a escrita [e, no caso das práticas de numeramento, envolvem a leitura e a escrita parametrizando de alguma forma relações de quantificação, mensuração, classificação], geradas por processos sociais mais amplos, e responsáveis por reforçar ou questionar valores, tradições e formas de distribuição de poder presentes nos contextos sociais" (idem, p. 75).

De modo especial, o conceito de práticas de numeramento nos ajuda a contemplar as práticas matemáticas dessas mulheres e desses homens de pouca referência escolar em suas atividades laborais, engendradas por relações de gênero e forjadas em uma cultura escrita em meio a faltas materiais e inclusões precárias em direitos sociais, opressões, engajamentos e lutas.

\section{PRÁTICAS DE NUMERAMENTO E RELAÇÕES DE GÊNERO NAS ATIVIDADES LABORAIS NA ASSOCIAÇÃO DE CATADORAS E CATADORES DE MATERIAIS RECICLÁVEIS}

As atividades laborais discutidas neste artigo foram desenvolvidas por 62 mulheres e por 12 homens participantes de uma associação de catadoras e catadores de materiais recicláveis. ${ }^{4}$

Desde o início da associação, em 2002, as mulheres foram maioria no grupo. Com diferentes idade e experiências como catadoras, essas mulheres conferiam valorações distintas a esse modo de organização de trabalhadoras e trabalhadores. Assim, se muitas (especialmente as mais velhas) se uniam em defesa da associação, muitas também, em diversas situações, desafiavam acordos, realizavam enfrentamentos com as outras mulheres, retiravam o apoio a decisões coletivas. Entretanto, mesmo no dissenso, sobressaía na participação dessas mulheres a marca da coletividade e de um engajamento maior que o dos homens na defesa da associação e na gestão coletiva do trabalho.

3 Segundo Magda Soares (2004, p. 104), os “novos estudos sobre letramento”, realizados sob uma perspectiva social e etnográfica, consolidam-se nos anos de 1990, trazendo "além de novos princípios e pressupostos teóricos, alguns instrumentais para a análise do fenômeno do letramento".

4 São considerados materiais recicláveis: papel, papelão, embalagens Tetra Pak (de leite, suco e outros alimentos), garrafas PET, sacos e sacolas plásticas, embalagens plásticas, isopor, canos e tubos de PVC, vidros (garrafas, frascos, copos), metais (latas de alumínio, embalagens de conservas), objetos de cobre, sucatas e ferragens. 
A maioria dos homens associados não se envolvia com o modo de organização coletivo da associação e afirmavam estar ali de passagem: "aqui não é pra mim" (Pedro), " "Tô esperando um outro babado" (Sebastião). Poucos homens acompanharam a associação desde a sua fundação e havia uma rotatividade constante na participação masculina. Nas enunciações analisadas dos homens ou sobre eles, podemos ler marcas de um trabalho que se pauta muito mais pelos modos individuais de organização do que por um fazer coletivo. Outra marca que apareceu foi a da consideração por eles e por elas de que o trabalho de catação "é um trabalho de mulher", estando reservadas para os homens as atividades mais sofisticadas e nobres, ligadas à operação de máquinas e desmontagem de equipamentos.

$\mathrm{Na}$ organização dessa associação, na qual prevalece uma maioria feminina, existem distinções, hierarquias de gênero, valorações diferenciadas sobre as atividades exercidas no espaço do trabalho e sobre quem as exerce. Enfrentamentos, disputas, tensões e desigualdades de gênero se estabelecem nesse espaço.

\section{MEDIÇÃO E CONTROLE}

Se os homens, especialmente os mais pobres, perdem terreno no gerenciamento e na manutenção da casa por não conseguirem "assumir o papel de mantenedores" (Soihet, 2000, p. 368), o espaço do trabalho sobrevive como o lugar do exercício da autoridade masculina, preservado discursivamente como $o$ verdadeiro lugar do homem. No trabalho da associação, eram eles quem preferencialmente assumiam posições decisórias, de controle e que demandam avaliações e critérios objetivos - que se devem manter isentos de subjetividades - e critérios circunstanciais ou intuitivos. Os catadores homens, que eram minoria se considerarmos os números de associados e de associadas, assumiam o trabalho com as prensas e o controle da balança, como sugeriu esta enunciação da catadora Ana, referindo-se ao procedimento de pesagem de vasilhas que às vezes ela encontrava no meio dos materiais que seriam reciclados e tinha a intenção de comprar da associação:

Ana: [...] toda hora que eu pegava alguma coisa lá pra pesar, se eu não sabia o peso, eu pedia pro Paulo: "Pesa isso aqui pra mim"; pedia pro Juca; ele pesava, mas a pessoa pagava por aquilo que ela levava.

Essa exclusividade dos catadores homens no controle da balança e da prensa reatualiza e se baseia no discurso de que homens são mais hábeis que mulheres para operar máquinas e instrumentos. Nesse caso, o manuseio da balança envolvia situações de conferência e controle que remetem a uma racionalidade de matriz cartesiana e assim a uma matemática de matriz cartesiana - "um modo de pensar e fazer matemática que busca e valoriza a clareza da linguagem, a objetividade, a certeza, o recurso a demonstrações, à generalidade das proposições matemáticas, a

5 Neste artigo, usamos nomes fictícios para preservar a identidade das pessoas envolvidas. 
segurança e a perenidade do que se assegura como o conhecimento matemático" (Souza; Fonseca, 2010, p. 306) -, uma vez que esse controle não se fia numa avaliação do peso por estimativa com base em experiências vividas: todo material deve ter a medida de seu peso comprovada pela pesagem precisa, de balança, que the atribui um valor público, legitimado pela conferência de um equipamento e pela expressão numérica.

Assim, ao mesmo tempo em que a eles era reservado o controle das prensas e da balança, a elas tocava o trabalho minucioso de triagem dos materiais a serem reciclados: trabalho miúdo, cujo rendimento é pouco visível, que envolve a limpeza e a separação dos componentes e exige paciência e despojamento. Em contrapartida, na maioria das vezes, eram elas quem carregam pesados fardos de materiais para a balança:

Ângela carrega dois fardos de PET para a balança enquanto Lúcio espera para realizar a pesagem.

Pesquisadora: Você não sabe mexer na balança?

Ângela: Lúcio sabe tudo e ele consegue arrumar a balança quando ela "tara"... se não colocar certo, dá prejuízo, ou pra nós [associação] ou pra eles [compradores].

Nessa cena e em tantas outras, o tipo de racionalidade valorizada e a verdade instaurada sobre a capacidade masculina de controlar máquinas e equipamentos conformam diferenciações nas práticas de numeramento autorizadas para homens e aquelas permitidas para as mulheres. A detenção pelos homens da informação sobre o peso, e consequentemente sobre o valor em dinheiro a ser pago sobre o total do material pesado, definia um controle sobre a produção feminina, cujo exercício era autorizado por elas como efeito do discurso de que o homem opera máquinas e cálculos melhor que a mulher.

Mas há também, nessa e em outras cenas e enunciações, o tensionamento de outro discurso, aquele que posiciona a mulher como fisicamente frágil, quando elas arrastavam pesadas sacas de material para a balança, por exemplo, e principalmente quando tematizaram a capacidade de trabalho das mulheres em seus depoimentos: "É uma pena a Dora não poder ficar [na associação]. Ela é muito trabalhadeira. Vale muito mais que esses homens que fica aqui. Pega aquele tanto de PET e num instante limpa tudo" (Elisa).

Nesse sentido, parece que o discurso feminista - que é mobilizado e que se constitui nas lutas contra as assimetrias nas relações de gênero (Fischer, 2001; Louro, 1995; 1996;1997; 1998) - exerce muitos efeitos nas práticas dessas mulheres trabalhadoras. Um dos efeitos pode ser lido no modo como elas procuravam tornar o espaço da associação em um espaço de relações de trabalho mais igualitárias entre mulheres e homens e buscavam cumprir as regras acordadas em assembleia. Outro efeito apresenta-se nas vezes em que, ao comparar o seu desempenho ao dos homens, elas procuravam se mostrar capazes de realizar as mesmas tarefas que eles (como o trabalho físico, por exemplo) e de modo mais competente: "Vale muito mais que esses homens que fica aqui". 


\section{ORGANIZAÇÃO E REMUNERAÇÃO DO TRABALHO}

Todavia, muitas vezes, quando se queixavam da desigualdade nas relações que as envolviam, as catadoras as consideravam como efeito da desunião do grupo de associadas e associados. É o que motivou o desabafo da catadora Ana quando se referiu às gorjetas que motoristas de caminhões, ao buscarem material reciclável no galpão da associação, distribuíam exclusivamente aos catadores homens, mesmo quando catadoras os ajudavam a carregar o material:

Ana: [...] vão supor, vai carregar o caminhão, vão supor, vai carregar o caminhão do [...], as mulheres, as mulheres podiam encher os caminhão tudo, ajudando os homens, só quem ganhava era os homens; por exemplo, ele tava, o outro não tava, podia ter seis mulher lá, se tivesse dois homens, os dois homens ganhava e as mulher não ganhava nada. Isso tudo é, isso tudo é desunião. Se o seu fulano vai ganhar dez, por que que não divide um pra cada um? Ou então ninguém ganha nada. Falava, não adiantava. Às vezes, os homens tava carregando os fardo pro carro, às vezes, as mulher tava lá fora carregando o caminhão de grosso [papelão], de outro material, por que que só aqueles cá que podia ganhar e os de lá não podia? Então, pra mim aquilo ali tudo era uma falta de união.

Assim, quando consideramos o estabelecimento de relações desiguais na divisão do trabalho ou na remuneração concedida a quem trabalha como efeito de uma desunião um tanto generalizada, permanecem obscurecidas as desigualdades de gênero instauradas nos modos de organização masculinos, que sujeitam as catadoras - e aos quais elas se sujeitam - a desempenhar certas atividades mais pesadas e ou menos valorizadas, ou que definem remunerações diferenciadas para elas e eles. As avaliações que fazem com que essas mulheres identifiquem, questionem, mas se sujeitem a essas relações desiguais, forjam-se em práticas de numeramento em que cálculos e princípios para o equacionamento da gestão do trabalho e do ganho submetem-se à força das relações de gênero que impregnam as atividades laborais.

Contudo, como membros de uma associação que integrava o Movimento Nacional de Catadores de Materiais Recicláveis, ${ }^{6}$ as catadoras se apropriaram de construções discursivas que se constituem nos movimentos sociais e que também os constituem. Assim, essas mulheres se posicionavam como defensoras do sonho da produção coletiva, numa situação mais segura e digna (embora menos rentável) do

6 Desde 2001, as catadoras e os catadores têm forçado a sua entrada no cenário nacional pela organização, no Brasil, do Movimento Nacional de Catadores de Materiais Recicláveis. Sobre esse movimento, ver documento no sítio eletrônico do Movimento Nacional de Catadores. Disponível em: <http://www.mncr.org.br/box_2/instrumentos-juridicos/classificacao-brasileira-de-ocupacoes-cbo/>. Para se compreender melhor esse tipo de trabalho no Brasil, sugerimos os estudos de Lea Pinheiro Paixão (2003). A autora aponta a precariedade de estudos acadêmicos sobre catadoras e catadores: "Parece que, marginalizados socialmente, também permanecem na penumbra do mundo acadêmico" (Paixão, 2003, p. 271). 
que a catação no lixão. ${ }^{7}$ No lixão, segundo relatos que as catadoras fizeram quando as entrevistamos, imperava a lei do mais forte, a solução individual, a exploração sem qualquer árbitro. Apesar disso, algumas mulheres, quando tinham oportunidade ou necessidade, optavam, ainda que veladamente, por trabalhar alguns dias no lixão:

De dentro da sala de aula, as alunas veem outra catadora [Dora] chegando ao galpão de triagem dos materiais. Escutamos, lá de dentro, Dora justificando-se para as outras catadoras que se encontravam lá fora:

Dora: Eu tava sumida porque tava doente.

As quatro catadoras que estão lá fora escutam, sem fazer comentários, a explicação de Dora.

$\mathrm{Na}$ sala de aula, Judite diz:

Judite: Agora tem esse problema da Dora, que tava é no lixão trabalhando.

Os homens, por sua vez, não se preocupavam em disfarçar o posicionamento que assumiam, que os fazia optar declaradamente pela solução que lhes fosse mais vantajosa:

Pedro: $\mathrm{O}$ [preço do] material caiu demais. Tá barato demais. O PET nós vendia a um e quinze. Agora é quarenta centavos. Abaixou demais. E a produção caiu demais.

Marta: A produção caiu, uai.

Pedro: Se a produção subir, o dinheiro sobe; se a produção baixar, o dinheiro abaixa.

Pesquisadora: $\mathrm{E}$ os compradores tão vindo comprar?

Alda: Ói o material aí, minha filha. [Aponta com a cabeça o material estocado no galpão sem que o tenham limpado] Não tem produção. O material aí...

Pedro: $\mathrm{O}$ povo não tá aqui, sabe por quê? Um muncado tá no lixo, sabe por quê? Porque o lixo tá dando mais do que aqui na associação. Aqui é mais caro, e lá no lixão é mais barato. Lá eles vende o PET solto a quinze centavos dentro da bolsa. Se você fizer trezentos quilos lá, você ganha quase trinta reais. Aqui é quarenta centavos. Aqui, se trabalha sete hora e meia, é sete real e cinquenta. $\mathrm{O}$ que adianta? Adianta nada. $\mathrm{O}$ material aqui é mais caro e tem que vender o material todo pra dar mais dinheiro. Se sai aqui cinco mil, seis mil tonelada, é melhor procê. Agora não tá saindo não.

7 Antes da organização da associação, essas catadoras e esses catadores trabalhavam em um lixão da cidade. Durante o período de realização do trabalho de campo, o lixão foi reativado e muitas catadoras e catadores retornaram a esse trabalho temporariamente, até que ele fosse novamente fechado pelo poder público municipal. A associação se mobilizou na luta pelo fechamento do lixão engajando-se com essa ação na luta do Movimento Nacional de Catadores de Materiais Recicláveis pelo fechamento dos lixões no país. 
Assim, como observamos na interação citada, bem como em tantas outras discussões e argumentos de catadoras e catadores, práticas de numeramento permeiavam as decisões relacionadas às tensões entre o compromisso com os princípios e o sucesso da associação e o gerenciamento das próprias demandas individuais. Tais práticas eram muitas vezes inspiradas por uma linha de raciocínio que levava à identificação dos (e à opção pelos) melhores ganhos individuais, numa avaliação que não raro tomava a quantificação como critério primeiro e que suplantava os imponderáveis (dignidade, pertencimento, solidariedade) na configuração dessas práticas.

Por sua vez, a perspectiva de união que sustentava o movimento associacionista era parametrizada por aquilo que associadas e associados consideravam ser justo com os que trabalhavam. Em um dos momentos da pesquisa de campo, encontramos Ana arrastando para fora da sala de aula pesadas sacas de papel branco, para que as aulas pudessem ter início:

Ana: Esse papel foi limpo ontem, se ficasse aqui fora ia embora. O que você acha da situação: outro dia nós ganhamos muito branco, deu mais de quinhentos quilos e nós só queremos dividir com quem trabalhou. Vem esse povo que fica no lixão [faz sinal com a cabeça para o homem que chegou quando arrastávamos as sacas de material e passou direto sem sequer se voltar quando ela lhe pediu que a ajudasse a arrastar as sacas] atrapalhando a gente e ainda quer receber. O que você acha?

O que Ana reclamava para si e para as outras mulheres que haviam trabalhado na limpeza do papel era o direito de não repartir o fruto do seu trabalho com aqueles e aquelas que não trabalharam. Essa situação de exploração produz relações muito específicas com as contas, assim forjando práticas de numeramento em que valores numéricos, pesos e quantidades em dinheiro são cotejados com outros valores como segurança, justiça e indignação. É o que se pode depreender na interação que reproduzimos a seguir, como em outras tantas ocasiões em que testemunhamos desconforto e revolta das catadoras:

Numa manhã, flagramos Ana e Simone conversando consternadas.

Simone: Roubaram o grosso [refere-se a papelão e plástico duro].

Ana: Essa quinzena nós não vai tirar nem trinta reais. Geraldo [outro catador] recebia cento e oitenta por mês para tomar conta à noite, esse pessoal não quis porque nós tava tirando cento e quarenta por mês, e ele cento e oitenta. Agora nós não tira é nada.

Simone: Nessa quinzena, nós tiramos oitenta e cinco centavos a hora. Agora a gente não vai tirar é nada. A gente trabalha de dia, e os outros roubam de noite.

Nessa cena, Ana, aluna em processo de alfabetização, portanto não autorizada a participar das aulas de matemática - conforme o projeto da escola que ali funcionava-, e Simone, que afirmava "ter muita dificuldade com as contas", remeteram-se 
com propriedade a cálculos matemáticos. As operações matemáticas que permearam as falas de Ana e Simone envolveram médias aritméticas, subtração com ideia comparativa, grandezas proporcionais... Mas, no discurso, desempenharam o papel de argumento e não de mera informação sobre valores. Deslindaram a teia de relações de poder por meio das quais seus ganhos estavam sendo subtraídos. Fazer contas significa, nesse caso, constatar uma situação de exploração e inquietar-se diante dela, perder o sono e o sossego, estar sempre vigilante, como relatou Ana em uma oficina realizada sobre as contas que fazemos no nosso dia a dia:

Ana: As contas essa noite me perturbou e não deixou eu dormir. Eu não sabia se eu pensava no material que tá aqui dentro no galpão ou se eu pensava no material que tava lá dentro da escola [limpo para a venda]. Então eu fiz conta demais. [...]

Essa noite eu fiz conta: eu ver aquele dinheiro [referindo-se ao ganho que teriam na venda do material limpo] chegando pra associação; e como nós sofremos um tempo atrás, papel que eu apanhei e limpei [referindo-se ao material que fora roubado em outra ocasião]. Será que eu vou encontrar lá aquele objeto? Será que eu vou encontrar? Será que ele só vai entrar e nós, e nós não vão nem ver o dinheiro? Eu passei a noite sem saber, sem dormir.

As formas de organização do trabalho na associação engendravam, pois, variadas tensões. No início da associação, por exemplo, a forma de organização do trabalho era por produção: o ganho era calculado pela quantidade e qualidade do material que a pessoa separasse, limpasse e levasse para a balança (controlada por um homem). Essa situação era mais vantajosa para os homens que para as mulheres, porque, como nos relatou Ana, "aqueles [homens] que pegavam material, que pegava alumínio, pegava cobre, pegava as coisas, eles atingiam até trezentos real... enquanto nós [as mulheres] atingia, por exemplo, é, no começo com cento e oitenta, depois nós fomos subindo de pouco a pouco, nós parô em duzentos e trinta e um". Em termos monetários, uma desvantagem de sessenta e nove reais na remuneração alcançada pelas mulheres em relação àquela atingida pelos homens; em termos de opressão, essa desvantagem é impossível de ser mensurada.

\section{VIOLÊNCIA, RACIONALIDADE E NATURALIZAÇÃO}

No excerto discursivo a seguir, Paulo procurou justificar por que as catadoras não "pegariam o alumínio". Ecoando o discurso de que os homens são mais hábeis que as mulheres para lidar com máquinas - portanto, desmontar um motor, limpar, separar o cobre e o alumínio -, Paulo estabeleceu que a seleção dos metais seria por natureza atribuição dele, e esse material seria, então, naturalmente dele. Afinal, como consequência dessa capacidade, era também natural que ele ganhasse mais que elas, que segundo ele acabariam por se beneficiar com esse arranjo:

Paulo: Uma vez deu oitenta quilos de alumínio de uma vez. 
Pesquisadora: E por que você pegava só o alumínio, Paulo?

Paulo: Porque o alumínio era mais fácil de ganhar dinheiro.

Pesquisadora: Foi esperto, hein, Paulo?

Paulo: Não, porque, assim, elas não pegava alumínio praticamente, [...] vem carro aí, elas não sabia quebrar o motor, e tinha outros alumínios pesados, elas não sabia, eu sabia, e falava "vou pegar pra mim". Pode pegar, gente? Pode, que vai ser bom que vai pegar, né, porque é meio a meio, se eu pegar alumínio pra mim, vão supor, se ele dá dois quilos, ele custa três reais, fica pra mim um e cinquenta e pra associação um e cinquenta. Então aí dava certo, né? Eu pegava e começava a quebrar os alumínios. O cobre era cinco reais, eu pegava, vai ser o quê? Eu ganhava dois e cinquenta pelo cobre, só que pra dar um quilo de cobre eu ganhava dois quilos de alumínio, porque era mais fácil, né, o cobre sempre era mais caro, então eu ganhava alumínio, porque era mais barato.

Pesquisadora: Ah, mas como é que é isso, era um pra você e um pra associação? Paulo: Aqui era um quilo pra mim e um pra associação, qualquer coisa era meio a meio.

Entretanto, como nos mostrou Ana, a exclusividade para pegar o alumínio não era assim uma situação tão consensual como pareceu na enunciação de Paulo. No relato das mulheres, pairavam o questionamento da forma de organização masculina desse espaço e o temor perante as ameaças a quem ousasse desafiá-la, reclamando seus direitos:

Ana: [...] chegava dois caminhão pra nós, jogava lá na esteira, de repente nós acabava com aqueles trem, só que tinha um, era seis blocos, tinha o bloco da sacolinha, tinha o bloco do grosso, tinha o bloco do papel, papelão, papelão grosso, sacolinha, papel branco e o [...], cinco blocos, cada bloco com seis pessoas, duas ia pra esteira, aquelas quatro ia limpar, aquelas quatro tinha que dar conta daquele material limpo de qualquer bloco, quando dava onze horas não tinha mais nada, nós ia embora pra casa; só tinha uma desvantagem, que o pessoal que tava no bloco que pegava o ferro, pegava o alumínio, pegava o cobre, aí tinha o bloco dos homens e não tinha jeito mesmo, nunca teve e nunca vai ter. Pesquisadora: Por quê? Como que é?

Ana: Eles pegavam o alumínio, pegava o metal, catava o alumínio fino como o grosso, o metal e o cobre; pra nós só saía... Qualquer outro bloco, só saía as outras coisas.

Pesquisadora: E saía mais caro, o alumínio?

Ana: Era mais caro.

Pesquisadora: E como que eles pegavam?

Ana: Tirando da gente; eles não deixavam. Quatro blocos só vivia no prejuízo. Pesquisadora: E quantos homens eram? E quantas mulheres eram?

Ana: Seis homens... Ah, minha filha, vão supor, eu tô nesse bloco aqui. Tá eu, tá você, tá aquela menina ali, nós tão de seis aqui. Só um porém: lá em cima tem 
um pegando só o nosso material, que é o [...], pegando o alumínio, o cobre, ele não vem até você.

Pesquisadora: Hum... hum.

Ana: E fica só lá com ele; porém, não adianta você brigar. Quantas e quantas vezes, pra vim, aquele marido da Cilene, que é o Otávio, hoje ele saiu de lá até por conta própria, falou que o litro de gasolina não custava nada, podia ficar dois, cinco meses tentando... [o catador ameaçava atear fogo em Ana].

Pesquisadora: É?

Ana: Eles não pegavam outros [materiais metálicos], mais pequenos, que nem o Doril, Novalgina, ${ }^{8}$ assim; não pegavam e eu não deixava passar, eu ficava lascada, e tudo que era dos outros [metálicos miúdos] tava lá pra cima e eles não pegavam, e eu catava e colocava dentro da bolsa, e eles falava que tinha que comprar um litro de gasolina, um falava assim: "Eu compro a gasolina". O outro dizia: "eu ponho fogo" [ameaçando atear fogo em Ana].

Era aquelas viagens de gente [referindo-se a catadoras e catadores que acompanhavam a cena], que não me deixa mentir, e vinha minha menina: "Mãe, pelo amor de Deus, mãe, para de gastar essa conta de trem mãe, eles tão só que ameaça que vai pôr fogo na senhora". "Minha filha, eles não pode me queimar sendo que eu tô aproveitando do que vai jogar fora”.

Situações como a relatada por Ana alertam que, na análise das práticas de numeramento no espaço laboral dessas mulheres e desses homens, é preciso considerar sua produção em meio a situações de violência contra a mulher.

Quando elas deixavam de coletar materiais recicláveis mais caros, como o cobre, por exemplo, porque eles (os homens) ameaçavam queimá-las ("eles falava que tinha que comprar um litro de gasolina, um falava assim: 'Eu compro a gasolina'. O outro dizia: 'eu ponho fogo' [Ana]), seus ganhos estavam sendo subtraídos e elas entendiam isso, embora não vissem maneiras de reagir.

Quando duas catadoras deixaram de denunciar a ocorrência de roubo de material que elas haviam limpado porque "o homem falou que tinha uma corrente lá pra nós, ${ }^{9}$ e a gente que é mulher tem medo mesmo" [Graça], elas se resignavam a sobreviver com menos dinheiro, mas tinham de criar novas estratégias de gestão do pouco dinheiro que tinham para sobreviver.

Quando uma mulher saiu de casa com uma filha e um filho, fugindo da violência do marido, e mudou "para um barraco" [Milva], tendo então de arcar sozinha com os custos do aluguel, mais uma vez a gestão das despesas e a produção de receitas demandavam esforços e criatividade renovados a cada dia.

Quando precisavam continuar vivendo com um companheiro violento para não perder o barraco porque "aí ele já falou que mata" [Elba], ou quando uma delas decidiu revidar, "um dia cansei de apanhar e também bati nele; fomos os dois

8 Refere-se aos envelopes de comprimidos, que são feitos de material metálico.

9 No dizer da catadora, o homem ameaçava bater nelas com uma corrente de ferro. 
pra cadeia" e "aí a meninada ficou toda nas minhas costas" [Eva], há nos critérios de decisão sobre o que fazer de sua vida e da vida das filhas e dos filhos relações matemáticas marcadas pela violência de gênero (e por toda a dor que tal violência provoca).

Nas práticas de numeramento que essas relações conformam, há submissão à força física masculina e às justificações, menos ou mais explícitas, sobre $o$ direito do homem ao exercício de tal violência; nas poucas vezes em que revidavam, essas mulheres, diferentemente dos homens, tinham de arcar com os custos desse ato. São situações que oprimem, destroem, cerceiam, colocam limites e, promovendo relações de vantagens para os homens, marcam as relações matemáticas das práticas laborais com os sentidos da limitação financeira, da flexibilidade e da criatividade na gestão dos parcos recursos, da urgência na produção de novas receitas, da autonomia e da solidão no gerenciamento da economia doméstica.

Ao discutirmos práticas de numeramento em atividades laborais de alunas e alunos da EJA, em uma sociedade na qual as ações de violência ${ }^{10}$ contra a mulher são históricas - mesmo com avanços legais nesse sentido, como a promulgação da Lei Maria da Penha em agosto de 2006, tais ações ainda são muito frequentes -, não podemos nos furtar à denúncia dessas relações de violência produzindo também relações com o conhecimento, configuradas nas (e que configuram as) práticas sociais.

Nas situações de violência aqui descritas e em tantas outras nas quais cotidianamente se vitimizam mulheres em nosso país, toda uma rede discursiva é tecida em relações de poder-saber que acabam por naturalizar a violência contra mulheres. Quando o homem é tido, nos discursos que identificamos nessas práticas, como mais capaz de controlar, como detentor de maior força física, como tendo uma natureza incontrolável e a mulher é tida como alguém que deve ser controlado, que é fácil de ser ludibriado, que se resigna a arranjos desfavoráveis ou que obedece à força física, mas também como aquela pessoa a quem cabe a responsabilidade de prover o lar, a violência contra a mulher encontra sua justificação.

Como alerta Foucault, "o mais perigoso na violência é a sua racionalidade" (Foucault, 2006, p. 319). Na associação, a forma de organização, mais vantajosa para eles do que para elas, produz práticas de numeramento marcadas pela exploração, pela opressão e por ameaças que envolvem experiências matemáticas bastante diferentes para mulheres e homens. Elas operam sempre com menos dinheiro que eles e, como são dadas às práticas de cuidado que às mulheres são naturalmente destinadas, precisam fazer esse pouco dinheiro render mais.

10 O conceito de violência é aqui tomado como o propõe Heleieth Saffioti (2004, p. 17): "ruptura de qualquer forma de integridade da vítima: integridade física, integridade psíquica, integridade sexual, integridade moral". Tomada por essa ótica das relações de gênero, a violência contra a mulher deve ser compreendida como produto das desigualdades históricas entre mulheres e homens e produzidas culturalmente sobre o modo como se tem definido masculinidades e feminilidades em nossa cultura. 
Talvez aí, nessa situação, apresentem-se modos de calcular bem mais sofisticados que os cálculos masculinos. Operar na falta, na dívida, no negativo, com as despesas maiores que a receita, exige uma habilidade matemática sofisticada e criativa, especialmente quando disso depende a sobrevivência própria e de outros. Como mostra Foucault, há todo um campo de correlações de força, no qual se deve tentar analisar os mecanismos de poder, procurando verificar como esse poder funciona, $o$ que faz e como o faz e a que estratégias de conjunto responde. Assim, ao tratarmos de relações de gênero e matemática nas atividades laborais, é para essa "analítica de poder" (Foucault, 1988, p. 80) que nos voltamos, procurando identificar seus mecanismos e como tais relações se encontram postas nessas práticas e o que elas pretendem produzir.

\section{PRÁTICAS LABORAIS, MATEMÁTICA ESCOLAR E RELAÇÕES DE GÊNERO}

Quando pensamos as práticas que acontecem nos espaços laborais, nos dispomos mormente a tematizá-las nas situações de aprendizagem escolares, não nos furtando a indagar sobre como tais práticas se conectam a modos de organização específicos nesses espaços, a relações entre as pessoas, a relações de gênero, ao trabalho remunerado, à educação das filhas e dos filhos, à subsistência, à maternidade, ao trabalho doméstico (não remunerado e frequentemente realizado exclusivamente pelas mulheres), entre outras, e como tais relações engendram práticas matemáticas. Por sua vez, não é possível nos voltar para tais práticas sem compreendê-las como ligadas a "estratégias de conjunto" (Foucault, 2006), em racionalidades específicas que se ligam ao Estado, à mídia, à justiça, à família, à matemática de matriz cartesiana, ao Ministério da Educação (MEC), enfim, a toda uma rede discursiva que se propõe a dizer para mulheres e homens, catadoras e catadores, alunas e alunos da EJA, como cada uma e cada um "deve ser, fazer e vivenciar, e como deve proceder e comportar-se” (Paraiso, 2002, p. 24).

Desse modo, nessas práticas de numeramento que têm lugar no espaço laboral na associação, podemos ler produções discursivas sobre mulheres (dadas ao cuidado, solidárias, companheiras, descontroladas, que só sabem brigar, frágeis, medrosas, fáceis de enganar etc.), sobre homens (centrados, racionais, fortes, capazes, competentes, habilidosos para o trabalho com máquinas e equipamentos, espertos, violentos, corajosos, individualistas, aproveitadores, ameaçadores etc.) e sobre as práticas matemáticas deles e delas, essas últimas muito mais pautadas por escolhas estranhas aos caminhos da razão.

As práticas de numeramento assim constituídas se naturalizam como masculinas ou femininas ao se afirmarem como práticas verdadeiras da mulher ou do homem, porque efetivamente assumidas por mulheres ou por homens.

Nessas práticas, são tecidas relações de poder nas quais se procura preservar um mundo organizado pela ótica masculina, produzindo saberes sobre mulheres e homens, e sobre elas e eles em suas relações matemáticas. Produz-se, assim, um tipo de matemática para as mulheres ao se considerar como naturais e pertencentes 
a elas as atividades que em nossa sociedade, marcada pela racionalidade de matriz cartesiana, são consideradas como menos elaboradas ou menos precisas porque parametrizadas por critérios que não se pautam exclusivamente na quantificação, na mensuração, na ordenação.

Pelos efeitos de verdades dessa produção, ocultam-se as outras tantas práticas de numeramento nas quais as mulheres se envolvem, como nos mostraram as catadoras quando narraram a realização de negócios que protagonizavam, como venda de produtos, compra de casa ou lote, venda de animais, roupas, cosméticos e utensílios diversos. Essas práticas tensionam uma produção discursiva sobre as práticas matemáticas femininas, que as considera como menos sofisticadas que as práticas matemáticas masculinas, essas últimas mais adequadas ao mundo dos negócios porque requererem maior rigor, precisão e controle.

As práticas matemáticas disponibilizadas para as mulheres catadoras, e de modo geral para as mulheres, e que se apresentavam em suas atividades laborais (seleção de materiais, limpeza desses materiais e do próprio galpão, ajuda aos homens para carregarem o caminhão etc.) eram restritas àquelas já naturalizadas como próprias do feminino (caracterizadas pela atenção a minúcias, pela disposição ao cuidado e pela posição de coadjuvante) e que quase sempre não se pautam pela matemática hegemônica - a de matriz cartesiana.

Nas práticas laborais na associação, os jeitos de ser homem e os jeitos de ser mulher, elaborados pelo discurso de natureza biológica, produzem jeitos de ser homem trabalhador e jeitos de ser mulher trabalhadeira e trabalhadora que reservam a eles o controle de máquinas e equipamentos e a elas trabalhos considerados menores: separação e limpeza do material. A força desse discurso se faz sentir na hegemonia de tal organização, mesmo numa associação composta em sua maioria por mulheres.

As práticas de numeramento são, portanto, espaços de tensões discursivas, forjadas num emaranhado de verdades produzidas sobre trabalho, matemática, escola e também sobre masculinos e femininos no trabalho, na matemática, na escola, constituindo-se, assim, de modo diferente para elas e eles. Reservam-se, socialmente e diferentemente para mulheres e homens, modos de participação nas atividades laborais que configuram práticas marcadas por distinções, desigualdades e opressões.

Pretendemos com essa discussão problematizar a universalidade e a naturalização do modo como exemplos de práticas laborais se apresentam na escola, especialmente nas turmas de EJA e nas aulas de matemática, e que operam com a noção binária da existência natural de trabalhos de mulheres e homens.

No intuito de lançar outros olhares sobre as práticas matemáticas escolares, enfatizamos não ser possível ignorar a assepsia do modo como a matemática comparece na escola (mesmo quando se evocam situações da vida real) ou conjurar tais situações como ilustrações de aula sem nos interrogar sobre como se constituem tais práticas, as tensões que as atravessam, as diferenças e desigualdades de gênero que se estabelecem ou são estabelecidas nessas práticas e como elas ecoam outras diferenças e desigualdades produzidas nas práticas escolares. 
Argumentamos que tais assepsia e naturalização produzem saberes sobre mulheres, homens e matemática ao se produzirem como naturais do masculino e do feminino determinadas atividades matemáticas que são demandadas nas diferentes situações vividas por alunas e alunos da EJA e que se organizam, para eles, dentro do controle de uma razão cartesiana e, para elas, destituídas do que se valora como componente dessa razão. Essa produção de saberes promove um modo de pensar as mulheres como seres em falta diante de uma pretensa racionalidade masculina e, por sua vez, a razão continua, pois, a ser produzida como posse do homem.

Compreendemos que no campo da educação de pessoas jovens e adultas os propósitos de se recomendar a mobilização de exemplos de atividades laborais na sala de aula constituem parte de um movimento legítimo de aproximação com os processos vivenciados por esses sujeitos - entre eles os que se referem ao trabalho.

O que buscamos aqui apontar é que as diferenças de gênero engendram desigualdades e violência contra as mulheres que se encontram em nossas salas de aula. Portanto, os propósitos legítimos de didatização das atividades laborais para promover o aprendizado de conteúdos escolares não podem esvaziar os sentidos das práticas sociais e nem destituí-las das tensões que as envolvem, pelo silenciamento, pela negação, pelas tentativas de ocultamento ou pela naturalização das desigualdades.

\section{REFERÊNCIAS}

Brasil. Ministério da Educação e do Desporto. Secretária de Educação Fundamental. Parâmetros Curriculares Nacionais (30 e $4^{\circ}$ ciclos). Brasília: MEC/SEF, 1998. v. 3.

- Ministério da Educação e do Desporto. Secretária de Educação Média e Tecnológica. Parâmetros Curriculares Nacionais: ensino médio. Brasília: MEC/SEF, 1999.

Ministério da Educação e do Desporto. Secretária de Educação Fundamental. Proposta Curricular para a Educação de Jovens e Adultos: segundo segmento do ensino fundamental (5a a 8a série). Brasília: MEC/SEF, 2002.v. 3.

Fischer, Rosa Maria Bueno. Mídia e educação da mulher. Uma discussão teórica sobre modos de enunciar o feminino na TV. Revista Estudos Feministas, Florianópolis: UFSC, v. 9, n. 2, p. 585-599, jul./dez. 2001.

Foucault, Michel. História da sexualidade: a vontade de saber. 13. ed. Rio de Janeiro: Edições Graal, 1988. v. 1. 1996.

.A ordem do discurso. 7. ed. Tradução de Laura Fraga Sampaio. São Paulo: Loyola, As palavras e as coisas: uma arqueologia das ciências humanas. 8. ed. São Paulo: Martins Fontes, 1999. A arqueologia do saber. 7. ed. Rio de Janeiro: Forense Universitária, 2005. Estratégia, poder-saber. 2. ed. Rio de Janeiro: Forense Universitária, 2006. v. 4. 
Fonseca, Maria da Conceição Ferreira Reis. Matemática, cultura escrita e numeramento. In: Marinho Marildes; Carvalho, Gilcinei Teodoro (Orgs.). Cultura escrita e letramento. Belo Horizonte: UFMG, 2010. p. 321-335.

Louro, Guacira Lopes. Gênero, história e educação: construção e desconstrução. Educą̧ão छ̊ Realidade, Porto Alegre: UFRGS, v. 20, n. 2, p. 101-132, jul./dez. 1995.

. Nas redes do conceito de gênero. In: Lopes, Marta Júlia Marques; Meyer, Dagmar Estermann; Waldow, Vera Regina (Orgs.). Gênero e saúde. Porto Alegre: Artes Médicas, 1996. p. 7-18.

. Gênero, sexualidade e educação: uma perspectiva pós-estruturalista. Petrópolis: Vozes, 1997.

. Segredos e mentiras do currículo. Sexualidade e gênero nas práticas escolares. In: Silva, Luiz Heron da (Org.). A escola cidadã no contexto da globalização. Vozes, 1998. p. 33-47.

PaIXão, Lea Pinheiro. Catadoras de dignidade: assimetrias e tensões em pesquisa no lixão. In: Zago, Nadir; Carvalho, Marília Pinto de; Teixeira, Rita Amélia (Orgs.). Itinerários de pesquisa: perspectivas qualitativas em sociologia da educação. Rio de Janeiro: DP\&A, 2003.

Paraiso, Marlucy Alves. Currículo e mídia educativa: práticas de produção e tecnologias de subjetivação no discurso da mídia educativa sobre a educação escolar. 2002. 284 f. Tese (Doutorado em Educação) - Universidade Federal do Rio de Janeiro, Rio de Janeiro, 2002.

Ribeiro, Vera Masagão (Coord. e Texto final). Educação de jovens e adultos. Proposta curricular para o $1^{\circ}$ segmento do ensino fundamental. São Paulo: Ação Educativa; Brasília: MEC, 1997.

SAfrioti, Heleieth Iara Bongiovani. Gênero, patriarcado, violência. São Paulo: Editora Fundação Perseu Abramo, 2004.

SoAres, Magda. Letramento: um tema em três gêneros. Belo Horizonte, Autêntica, 2001. . Letramento e escolarização. In: Ribeiro, Vera Masagão (Org.). Letramento no Brasil, reflexões a partir do INAF 2001. São Paulo: Global, 2004. p. 89-113.

Soinet, Rachel. Mulheres pobres e violência no Brasil urbano. In: Priore, Del Mary (Org.). História das mulheres no Brasil. 3. ed. São Paulo: Contexto, 2000. p. 362-400.

Souza, Maria Celeste Reis Fernandes de; Fonseca, Maria da Conceição Ferreira Reis. Razão cartesiana, matemática e sujeito: olhares foucaultianos. Educą̧ão छ̋ Realidade, Porto Alegre: UFRGS, v. 35, p. 303-318, set./dez. 2010.

Street, Brian. What's "new" in the literacy studies? Critical approaches to literacy in theory and practice. Current Issues in Comparative Education, Teachers College, Columbia University, Current Issues in Comparative Education, v. 5, n. 2, p. 77-91, may 2003.

Walkerdine, Valerie. The mastery of reason. London: Routledge, 1988. 


\section{SOBRE AS AUTORAS}

Maria Celeste Reis Fernandes de Souza é doutora em educação pela Universidade Federal de Minas Gerais (UFMG). Secretária adjunta de educação da Secretaria Municipal de Educação de Governador Valadares (MG). E-mail: celeste.br@gmail.com

Maria da Conceição Ferreira Reis Fonseca é doutora em educação pela Universidade Estadual de Campinas (UNICAMP). Professora da Universidade Federal de Minas Gerais (UFMG).

E-mail:mcfrfon@gmail.com

Recebido em maio de 2012

Aprovado em julbo de 2012 


\section{MARIA CELESTE REIS FERNANDES DE SOUZA E MARIA DA CONCEIÇÃO FERREIRA REIS FONSECA}

\section{Práticas de numeramento e relações de gênero: tensões e} desigualdades nas atividades laborais de alunas e alunos da EJA

O objetivo deste artigo é discutir as tensões de gênero que permeiam as práticas de numeramento que se forjam nas atividades laborais de alunas e alunos da Educação de Jovens e Adultos (EJA). O material empírico aqui mobilizado foi produzido no acompanhamento de atividades laborais e escolares em uma associação de catadoras e catadores de materiais recicláveis, por meio de oficinas pedagógicas, observação de aulas, entrevistas e registros de episódios. O referencial teórico dialoga com os estudos de gênero, com os estudos no campo do numeramento e sustenta-se nas contribuições de Michel Foucault relativas ao discurso. Destacam-se na nossa análise os jogos de poder definidos pelas relações de gênero que impregnam essas atividades laborais como um alerta contra uma naturalização das desigualdades de gênero que o silenciamento desses jogos tende a perpetuar, inclusive quando se tematizam essas atividades com finalidades pedagógicas.

Palavras-chave: relações de gênero; práticas de numeramento; atividades laborais; educação de jovens e adultos.

Numeracy practices and gender relations: tensions and inequalities in the work activities of female and male students at youth and adult education

This article aims to discuss the gender tensions that permeate the numeracy practices that are forged in the work activities of female and male students at Youth and Adult Education. 
The empirical material that served to this purpose was produced during educational workshops, observation of lessons, interviews and records of episodes in the work place of an association of recyclable material collectors. In this study, we operate with the Foucauldian concept of discourse, establishing a dialogue with the studies of gender and numeracy. In our analysis, we emphasize the power games defined by the gender relations that permeate these work activities, as a warning against the naturalization of gender inequalities that the silencing of these games tends to perpetuate, even when we discuss these activities for educational purposes. education.

Keywords: gender relations; numeracy practices; work activities; youth and adult

\section{Prácticas de numeracia y relaciones de género: tensiones y desigualdades en las actividades laborales de los/las estudiantes de la educación de personas jóvenes y adultas (EJA)}

El objetivo de este articulo es la discusión de las tensiones de género que impregnan las prácticas de numeracia y que se constituyen en las actividades laborales de los/las estudiantes de la Educación de personas jóvenes y adultas (EJA). El material analizado ha sido producido en el acompañamiento de las actividades laborales en una asociación de recolectores de materiales reciclables en talleres pedagógicos, observación de clases, entrevistas y registros de episodios. El supuesto teórico establece el diálogo con los estudios de género, los estudios en el campo de la numeracia y en las contribuciones de Michel Foucault a respecto del discurso. Señalamos en nuestro análisis los juegos de poder que se han definido por las relaciones de género que impregan aquellas actividades laborales como un alerta contra la naturalización de las desigualdades de género que el silenciamiento de esos juegos tienden a perpetuar, aun cuando estas actividades se utilizan con fines educativos.

Palabras clave: relaciones de género; prácticas de numeracia; actividades laborales; educación de personas jóvenes y adultas. 